\title{
Dinámica social en la comercialización de la madera en el municipio de Rosita, RAAN
}

\author{
Vilma Álvarez ${ }^{1}$, Silvia Martínez ${ }^{2}$ y Yamileth Escobar ${ }^{2}$ \\ 1. Departamento de Ciencias Sociales, Facultad de Humanidades. Universidad Centroamericana (UCA). Apartado 69. Managua, \\ Nicaragua.e-mail:Vilma@ns.uca.edu.ni \\ 2. Egresadas de la carrera de sociología, Facultad de Humanidades. Universidad Centroamericana (UCA). Apartado 69. Managua, \\ Nicaragua.
}

Recibido: abril 2005/ Aceptado: junio 2005

CADA ACTIVIDAD HUMANA SE BASA EN LAS REGLAS DEL JUEGO de una sociedad determinada. La dinámica que se teje en torno al comercio de la madera se enmarca en reglas establecidas, formales e informales, escritas y no escritas. Cuando los actores que participan en una actividad ven amenazada su posibilidad de apropiarse de los recursos sobre los que creen tener derechos, ya sea por restricciones y/o prohibiciones legales, buscan mecanismos para no ser excluidos y continuar recibiendo beneficios. En esa búsqueda, generan una serie de prácticas que, con el tiempo, sean legales o no, terminan institucionalizándose. Desde esta perspectiva, la comercialización de la madera opera en un marco institucional. El presente trabajo presenta los resultados del estudio entorno a cómo y por qué se institucionalizan las prácticas ilegales en el marco de la regulación comercial de la madera, en el municipio de Rosita. El análisis se enfoca en la diversidad de relaciones sociales que subyacen al proceso de comercialización.

Palabras clave: industria de la madera, regulación del comercio, mercadeo

\section{Introducción}

La madera constituye un recurso valioso en el país pero, a lo largo de la historia, su aprovechamiento se ha hecho de manera irracional y, actualmente, es un recurso en conflicto. En el proceso de su comercialización, se encuentran múltiples actores sociales intercambiando relaciones: dueños de bosque comunales y privados, madereros, Instituto Nacional Forestal- INAFOR, Alcaldías, transportistas, cargadores y Policía, entre otros. En su interrelación, se genera una dinámica social en la que subyacen prácticas institucionalizadas, unas con bases legales y otras no.

La pregunta que guió el estudio fue: ¿Cómo se institucionalizan las prácticas ilegales? El objeto de estudio fueron las relaciones sociales establecidas entre los actores de la comercialización de la madera. La hipótesis planteada fue: "La institucionalización se 
da por la conjunción de varios factores: contenido de la Ley forestal y flexibilidad en su aplicación; lejanía de mercados; poca incidencia de gremios, ONGs y agencias de cooperación en el negocio de la madera; y multiplicidad de intereses entre los involucrados."

La metodología utilizada en el estudio combinó aspectos cualitativos y cuantitativos. Los cualitativos consistieron en entrevista semi-estructurada y observación participante; se utilizaron para recabar los elementos subjetivos que ayudaran a entender mejor el fenómeno estudiado desde la perspectiva de los actores sociales. Los aspectos cuantitativos buscaron toda la información que permitiera ser cuantificada o medible (estadísticas sobre volumen de extracción de madera, costos, precios, impuestos, etc.).

La unidad muestral se estableció con 32 informantes clave como actores sociales involucrados en la dinámica de comercialización de la madera. Con estos informantes, se realizaron principalmente las entrevistas semi estructuradas.

\section{Regulación forestal: el marco jurídico donde se teje el comercio de la madera}

El recurso forestal pertenece al Estado, según el artículo 132 de la Constitución Política de Nicaragua. En ese sentido, la regulación forestal plantea las reglas del juego con las que deben participar los actores sociales interesados en el aprovechamiento forestal (ilustración 1).

Las normas técnicas y disposiciones administrativas del Instituto Nacional Forestal (INAFOR) establecen las directrices técnicas para el manejo sostenible del bosque tropical latí foliado y de coníferas. Son aplicables a toda persona natural o jurídica que se dedique a la actividad forestal en el territorio nacional. Estas disposiciones tienen por objeto desarrollar complementariamente las normas forestales vigentes, a fin de garantizar la sostenibilidad del recurso forestal; y su aplicación es competencia del INAFOR.

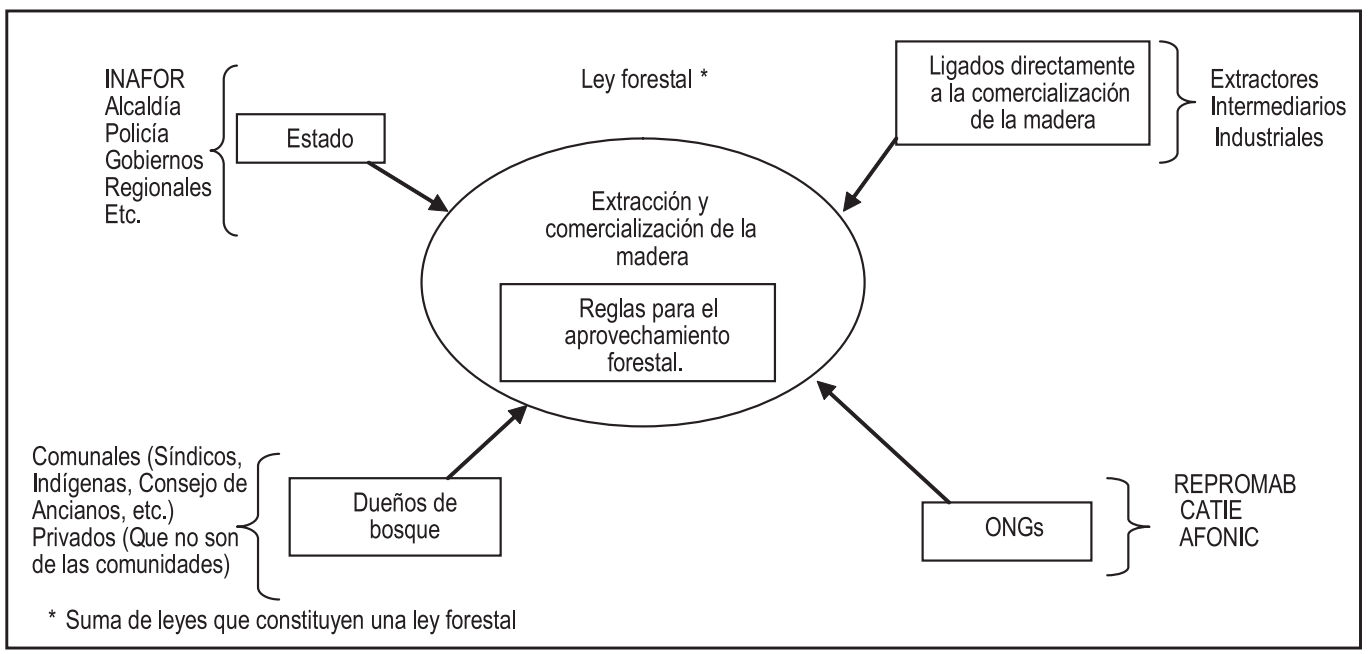

Ilustración 1. Rol de la regulación forestal y actores en torno al recurso forestal

Fuente: elaboración propia sobre la base de entrevistas, 2002. 
Para que una persona inicie legalmente la actividad maderera, debe seguir los siguientes pasos (reglas formales), teniendo presente el mercado y los contactos:

1. Focalizar el área de aprovechamiento.

2. Buscar un Técnico Foresta ${ }^{13}$ para que realice el Plan General de Manejo Forestal (PGMF), el Plan Operativo Anual (POA) y el Plan Mínimo o Plan de Reposición, según el área de bosque a aprovechar. Cada plan debe incluir el Censo comercial de las especies a aprovechar, cuyo diámetro mínimo de corta es de $40 \mathrm{~cm}$ DAP; excepto en el caso de Caoba, Cedro Real y Pochote, cuyo diámetro tiene que ser de $50 \mathrm{~cm}$ DAP; mapa base con la ubicación de los árboles; período de corta, tratamientos silviculturales; y remanencia: se debe dejar un 40\% de árboles de remanencia para la regeneración del bosque.

3. El Plan de Manejo debe ser presentado a INAFOR para su análisis, aprobación o desaprobación en un plazo de 30 días hábiles. Si en ese plazo no hay respuesta, el plan se considera aprobado y queda bajo responsabilidad del Delegado Municipal del INAFOR. También se requiere un permiso de título de propiedad o cesión de derechos (en el caso que no sea propio); aval de la Alcaldía; Aval del Síndico (en caso de que sea en propiedad comunal); Aval del Concejo Regional; y verificación in situ de las especies existentes.

4. Cuando el permiso forestal es aprobado, el Inspector, junto con los técnicos del INAFOR, proceden al marqueo (señalización) de los árboles a cortar.

5. El dueño del permiso puede extraer la madera. INAFOR mantiene un expediente de los metros a extraer y va controlando mediante la entrega de guías forestales. Por cada cinco metros cúbicos de coníferas y 10 metros de latí foliadas, se entrega una guía forestal.

6. Para la extracción se requiere maquinaria específica (por ejemplo: Tractores, squiders, montacargas, etc.) para la apertura de caminos primarios, secundarios y/o terciarios; patios de montaña o acopio; de estos últimos, la madera es transportada a la industria forestal y aserríos y a su destino final (sea mercado nacional o internacional).

\section{3. ¿Quiénes son los actores sociales en torno al recurso forestal?}

1) El Estado:

El Estado es legalmente el dueño del recurso forestal y, a través de sus diversas instancias, participa de su aprovechamiento: INAFOR, la Alcaldía, la Policía y los Gobiernos Regionales, entre otras.

El INAFOR regula y controla el aprovechamiento forestal, emitiendo permisos de aprovechamiento y gravando impuestos a la actividad forestal. Percibe el 75\% mientras el $25 \%$ corresponden a la Alcaldía municipal (cuya participación, también, está directamente ligada a la captación de impuestos por el aprovechamiento forestal: según la Ley 402, artículo 6, el INAFOR debe reintegrar a la Alcaldía el 25\% de los ingresos captados por el cobro de tasas por aprovechamiento del recurso forestal). 
Por su parte, la labor de la Policía en la parte forestal, está ligada al acompañamiento del cumplimiento de las funciones de las otras instituciones estatales y la protección de sus funcionarios, cuando lo requieran. De acuerdo con la Ley 228. capítulo 2, De las funciones de la Policía Nacional, en el numeral 6, la Policía debe coordinar y cooperar con el INAFOR para controlar el tráfico ilegal de madera.

Los Gobiernos Regionales son las autoridades de la Costa Caribe Nicaragüense encargadas de legitimar, en términos de gobernabilidad, a las autoridades comunales y velar por la sostenibilidad del recurso forestal en la región. Otorgan avales para el aprovechamiento forestal, instalación de aserríos en la Región y reconocen la autoridad de los Síndicos en las comunidades.

2) Dueños de bosque

Se denominan "dueños de bosque" a aquellas personas, individuales o comunales, que poseen en sus tierras extensiones boscosas y, por lo tanto, pueden aprovecharlas o ceder derechos de aprovechamiento, previa autorización del Estado que, legalmente, es el único dueño del bosque. Es decir, son dueños de hecho, no de derecho. Esta situación genera conflictos de orden social y político, en el sentido de que algunos dueños de bosque no admiten la autoridad del INAFOR sobre el recurso, generando dudas en cuanto al reconocimiento de la legitimidad que éste tiene en la zona.

Los dueños de bosques en fincas (bosques privados) es un grupo de características heterogéneas, algunos originarios de la zona y otros, no, interesados en la actividad forestal o en la actividad agrícola y/o ganadera.

Por otro lado, los dueños comunitarios de bosque es un grupo integrado por los pueblos o comunidades indígenas, que poseen el 80\% de las extensiones boscosas (Mendoza et al, 2001: 89) y, debido a la falta de recursos económicos para satisfacer sus necesidades y de alternativas para conseguirlos, se ven obligados a ceder los derechos de explotación del bosque a personas interesadas en invertir, o aceptar el financiamiento de la gestión del permiso de aprovechamiento por parte de algún comercializador, lo que implica que éste se convierte en el dueño de la madera, pagando precios muy bajos, o cambiándosela por productos básicos.

3) Actores con negocios en torno a la madera

Otros actores interesados en el recurso son los madereros, ligados directamente a la comercialización de la madera, quienes son el actor clave en dicho proceso, porque cuentan con capital económico, información y contactos en torno a los cuales se desarrolla la actividad.

Se identifican tres tipos de madereros:

a. Extractores: Extraen la madera que compran a los dueños de bosques comunitarios, de fincas privadas o de sus propias tierras; a veces, poseen equipo propio para la actividad o lo alquilan. Ocasionalmente, gestionan planes de manejo forestal como dueños, o cesionarios, o bien, financian a los dueños de bosque la gestión del permiso, asegurando 
de esa forma la madera. También puede ser que ellos mismos comercialicen la madera, o sólo sean intermediarios entre el dueño y otro maderero.

En la parte extractiva se requiere de otros actores para llevar a cabo este proceso, como son:

- Macheteros: Limpian las malezas.

- Carrileros: Hacen trochas para que la madera pueda ser extraída con el tractor.

- Motosierristas y sus ayudantes: Tumban el árbol con la motosierra.

- Cargadores: Se encargan de cargar y descargar la madera de los camiones.

- Operadores: Son los que trabajan directamente con las máquinas: conductor de tractores, squiders y montacargas, cada uno con sus respectivos ayudantes.

- $\quad$ En algunos casos, se requiere de fiscales ${ }^{4}$.

b. Intermediarios: Estos madereros sólo poseen capital económico. En la mayoría de los casos, no es propio, sino financiado. Su actividad se limita a comprar la madera tumbada, puesta en un punto geográfico determinado y llevada a otro; esta compra se puede hacer a los dueños de bosque o a madereros extractores.

c. Industriales o dueños de aserrío: pueden ser madereros individuales o empresas ${ }^{5}$; poseen aserríos permanente o portátiles; compran madera en rollo, la procesas en sus aserríos y, luego, la comercializan.

Estas categorías no son excluyentes unas de las otras. Los madereros pueden desempeñar diferentes roles en las diversas actividades, involucrándose en ellas, dependiendo de sus intereses. Se puede decir también que, de una u otra forma, todos son intermediarios.

4) Actores no gubernamentales

En la dinámica del comercio de la madera, también está presente la acción de diferentes Organismos No Gubernamentales (ONGs). Entre ellos, se encuentra la Red de Protección y Manejo de Bosques del Triángulo Minero y Prinzapolka (REPROMAB) ${ }^{6}$, cuyo objetivo es respaldar a las comunidades (Miskitas, Sumos y Ramas), a través de asesoría teórica y práctica sobre el valor económico de las diferentes especies maderables. Cuenta con el respaldo del Centro Agronómico Tropical de Investigación y Enseñanza (CATIE), organismo no gubernamental que impulsa el proyecto TRANSFORMA, financiado por COSUDE. Su función ha sido fomentar, capacitar y dar alternativas a las partes involucradas en el aprovechamiento forestal, mediante capacitaciones sobre el uso de las motosierras, por ejemplo.

Por su parte, la Asociación de Forestales de Nicaragua (AFONIC), es una asociación en el ramo forestal, que pretende brindar un servicio de calidad para elaborar Planes de Manejo, a solicitud de la parte interesada. Esta asociación cuenta con un equipo de entre 15 y 18 técnicos forestales afiliados. 


\section{Relaciones sociales entre los actores de la madera}

En la ilustración 2, se presentan las cadenas resultantes de la interacción entre los diferentes actores involucrados en el comercio de la madera, las cuales se construyen en torno al aprovechamiento y/o comercialización del recurso forestal. Deben leerse de forma vertical, de abajo hacia arriba.

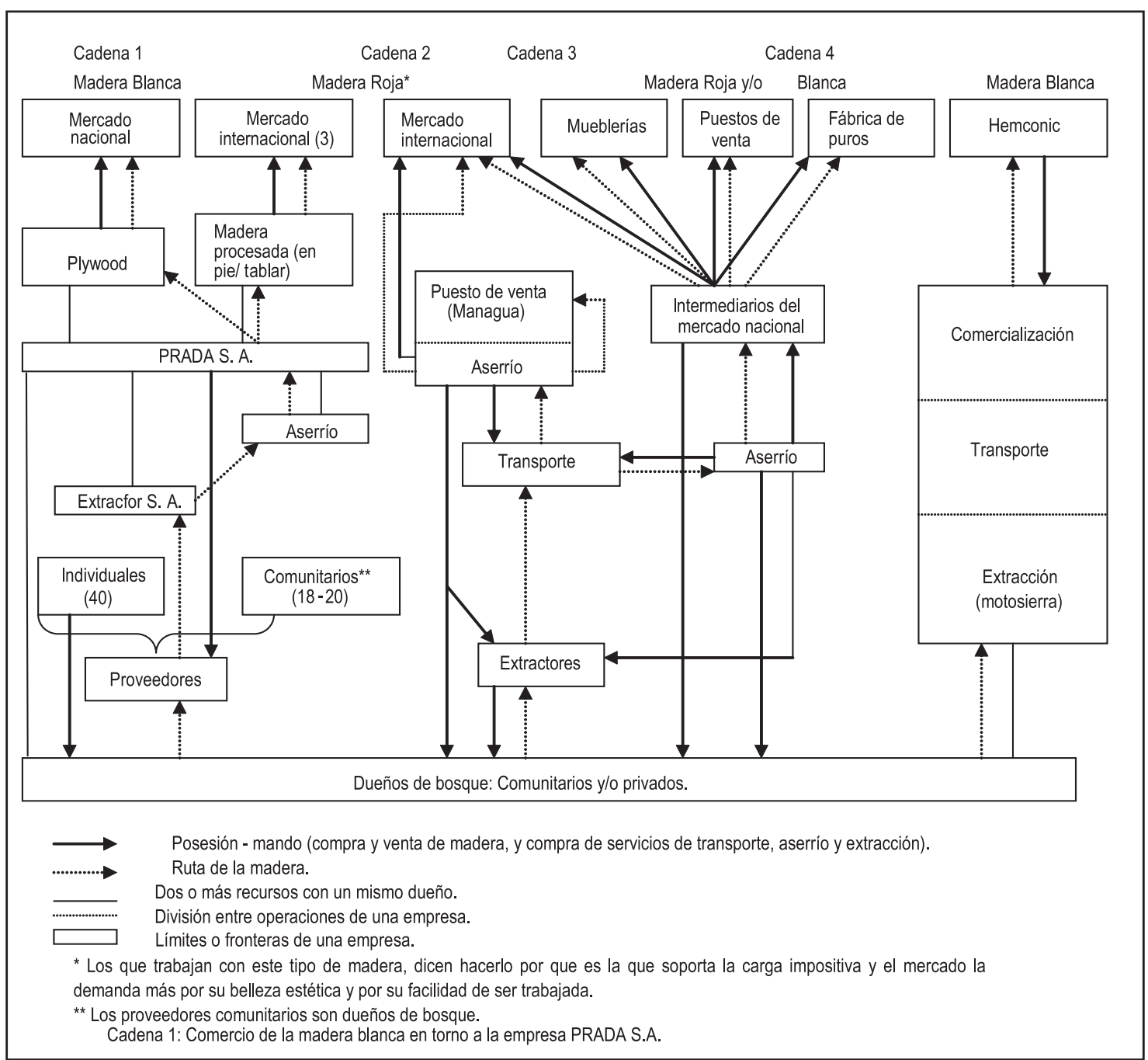

Fuente: Elaboración propia sobre la base de entevista, 2002.

Ilustración 2. Cadenas de comercialización de la madera en el municipio de Rosita

En la cadena 1 (madera Blanca), la empresa PRADA S.A. procesa plywood, trabaja aproximadamente con 30 especies de madera blanca que se usa en dos formas: una, en la transformación del plywood; y la otra, se transforma en el aserrío pasando de rollo a pie tablar y cuyo destino es el mercado nacional e internacional. PRADA S.A., a nivel local, es el actor clave, en el sentido que posee los recursos económicos que dinamizan la cadena, 
mediante el financiamiento de la actividad (por ejemplo, gestión de permisos, extracción e inclusive el transporte de la madera del lugar de extracción al patio de acopio que hay en la empresa) a sus diferentes proveedores ${ }^{7}$, tanto comunitarios como individuales. Esta empresa se abastece de madera de los Planes de Manejo ${ }^{8}$ que ejecuta directamente.

Extracfor S.A. es una empresa de extracción ligada a PRADA S.A. Se encarga de la extracción y transporte de la madera al aserrío; en el caso de los proveedores, se rentan los equipos y se le descuentan esos servicios en la liquidación.

En la última parte de la cadena (venta de la madera procesada), los clientes internacionales (Cuba, Costa Rica y Guatemala) se convierten en los actores claves, puesto que PRADA S. A. procesa la madera en dependencia de los estándares de calidad que requiere ese mercado. (Por ejemplo, madera sin ningún tipo de fallas, grado de madurez indicado, etc.).

En términos de rentabilidad, PRADA es la cadena de actores más competitiva. Cuenta con instalaciones en el Municipio y con relaciones directas con dueños del recurso que no tienen capital económico para llevar la madera más allá de las fronteras municipales. Trabaja con grandes volúmenes de madera (más de 20,000 m³ anuales).

En la cadena 2: Comercio de madera roja con bajos niveles de intermediación, está referida a la extracción y comercialización de madera roja. En este caso, el actor principal es el dueño del aserrío, quien posee el capital económico. Se abastece de madera por medio de dueños de bosque (a los cuales bien pueden financiarles la gestión de un permiso, o negociar una cesión de derechos para que ellos mismos tramiten su Plan de Manejo), o comprarla a madereros extractores. Paga por servicio de transporte para llevar la madera del patio de acopio al aserrío, donde recibe la primera transformación y se clasifica según su calidad en Fax, Select, Común 1, Común 2 y Común 3, siendo la primera la de mejor calidad. Pueden exportar inclusive la Común 1; sin embargo la común 2 y 3 la comercializan en un puesto de venta propio en Managua.

Ellos mismos exportan la madera, por tanto aparecen pocos intermediarios participando en el proceso de comercialización. Al igual que en la cadena 1, el actor clave es el comprador de la madera para la exportación. En este caso, el mercado internacional está conformado principalmente por Estados Unidos y República Dominicana.

En el caso de la cadena 3, el comercio de madera roja con altos niveles de intermediación, los actores clave son los madereros intermediarios, quienes trabajan de forma individual, tienen sus propios clientes, buscan cada uno su mercado y pueden estar involucrados en las diferentes fases de la actividad comercializadora, ya que pueden desempeñar diversos roles.

Algunos madereros poseen medios para extraer, transportar, aserrar y comercializar la madera, mientras que otros sólo sirven de intermediarios entre el extractor y otro intermediario. Unos comercializan con madera roja que va al mercado internacional y otros con madera blanca para el mercado nacional. En esta cadena, se observan altos niveles de intermediación y, al igual que en las cadenas anteriores, el actor clave es el cliente que demanda la madera de exportación. 
Por su parte, la cadena 4, a diferencia de las anteriores, es una cadena más integrada. El actor clave es la empresa minera Hemco de Nicaragua (Hemconic), ubicada en Bonanza, que trabaja con tres madereros que le proveen de madera blanca, la que compran para la mina y para los pozos. Quienes proveen la madera son dueños del recurso forestal, poseen motosierra con lo cual abaratan costos de extracción, la trasladan a Hemconic en sus propios medios de transporte y hacen los arreglos de comercialización, personalmente, con la empresa minera.

De acuerdo a cada una de las cadenas arriba presentadas, se procedió a identificar el conjunto de relaciones tejidas en su interior. Los criterios utilizados para elaborar las redes se basan en relaciones de: intercambio de bienes y servicios; poder e influencias; cooperación; solidaridad; alianzas; etc., establecidas entre los diferentes actores que participan en el proceso de comercialización. A continuación se presenta, en la ilustración 3, un diagrama que, a nuestro juicio, es el más interesante en términos de relaciones sociales entre por los actores a lo interno de las cadenas, basada en la comercialización de madera roja y blanca (cadenas 2 y 3 ):

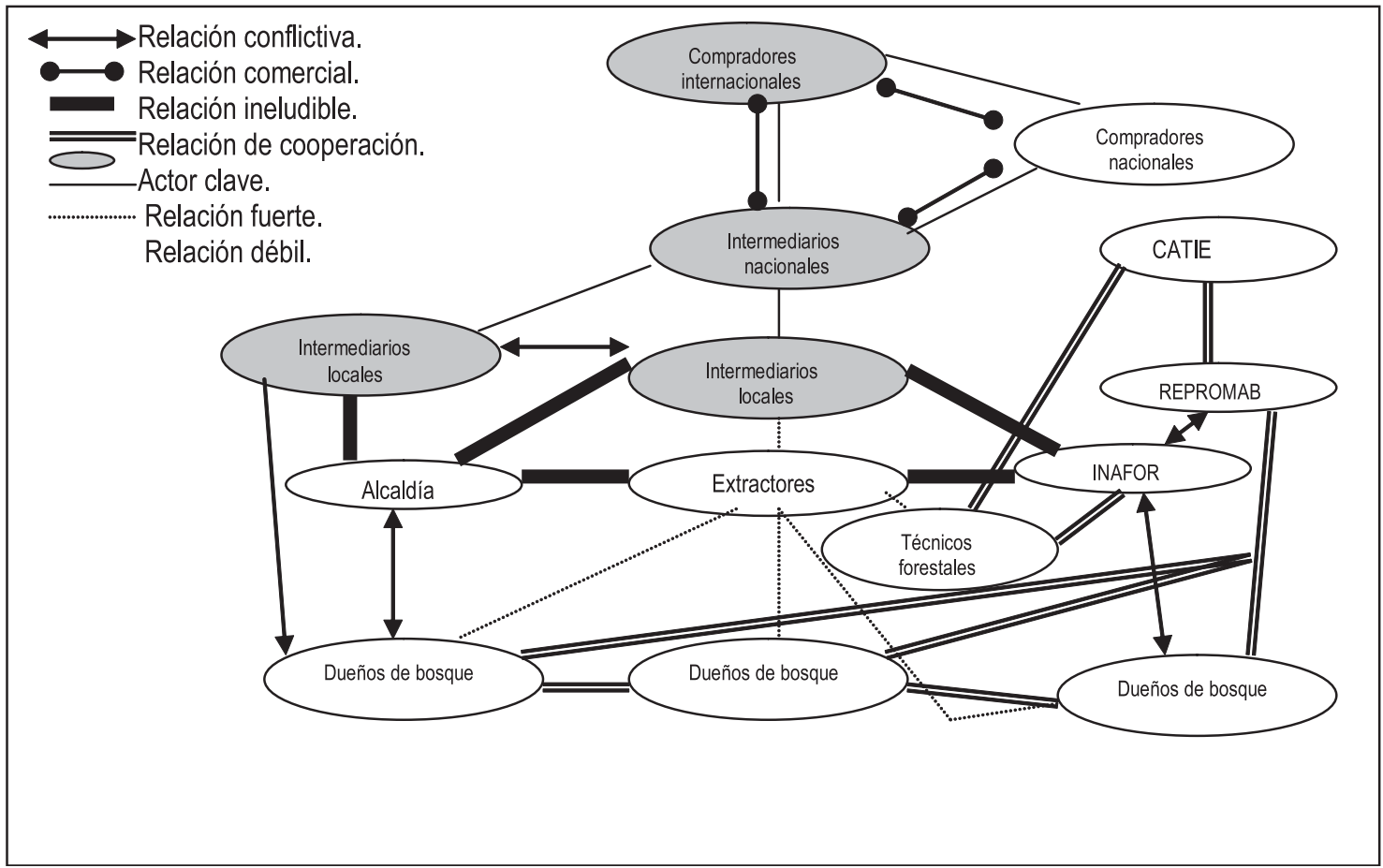

Fuente: Elaboración propia sobre la base de entrevistas, 2002.

Ilustración 3. Red social de actores en torno al comercio de madera roja y blanca

Puede apreciarse la relación que existe entre los diferentes actores, unas más fuertes que otras, dependiendo de la durabilidad de la relación. Cuanto más tiempo mantengan los lazos sociales, se hacen más fuertes, porque que se basan en la confianza, la cooperación y el beneficio mutuo. Así sucede en el caso de los intermediarios locales con los nacionales, 
pues no entregan su dinero a cualquiera. Tiene que ser alguien de confianza, que garantice su rentabilidad. Respecto a los compradores internacionales, la relación es fuerte siempre y cuando cumplan con sus requerimientos en la compra del producto: buena calidad, buen precio, etc. Entre los intermediarios locales, hay conflictos porque compiten por apropiarse del recurso, pero cuando lo obtienen, respetan ese derecho de propiedad (cuadro 1).

Por su parte, los dueños de bosques comunitarios mantienen una relación de cooperación y solidaridad entre ellos en el sentido de que se prestan las guías cuando tienen un pedido de madera y no disponen de tiempo para gestionarla; no sucede así con quienes les proveen, ya que la relación es débil: cuando se acaba el recurso, se acaba la relación. Con las organizaciones estatales mantienen una relación conflictiva, pues no quieren pagar por algo que consideran propio. Los conflictos se dan tanto a lo interno como a lo externo de las organizaciones, por apropiarse de la mayor cantidad de la ganancia generada por el recurso forestal.

Cuadro 1. Relaciones sociales conflictivas en el comercio de la madera

\begin{tabular}{|c|c|c|c|}
\hline Relación & Entre quiénes se da más & Cuándo ocurre el conflicto & Tipo de conflicto \\
\hline \multirow{9}{*}{ : } & INAFOR-REPROMAB & $\begin{array}{l}\text { Cuando REPROMAB quiere ser juez y parte } \\
\text { en el aprovechamiento forestal. }\end{array}$ & Político-económico. \\
\hline & $\begin{array}{l}\text { PRADA S.A.- Dueños de } \\
\text { bosque. }\end{array}$ & \multirow[t]{2}{*}{ Por altos costos de alquiler de maquinaria. } & \multirow[t]{2}{*}{ Económico } \\
\hline & $\begin{array}{l}\text { PRADA S.A.- Proveedores } \\
\text { individuales }\end{array}$ & & \\
\hline & $\begin{array}{l}\text { PRADA S.A.- Proveedores } \\
\text { comunitarios }\end{array}$ & $\begin{array}{l}\text { Cuando hay incumplimiento de acuerdos } \\
\text { que se establecen al inicio de las } \\
\text { negociaciones y por los bajos precios } \\
\text { pagados por metraje de madera. }\end{array}$ & Político-económico \\
\hline & $\begin{array}{l}\text { Proveedores individuales } \\
\text { - Dueños de bosque }\end{array}$ & $\begin{array}{l}\text { Cuando se da una competencia por la } \\
\text { obtención del recurso y bajos precios por el } \\
\text { mismo. }\end{array}$ & Socio-económico \\
\hline & $\begin{array}{l}\text { Intermediarios locales- } \\
\text { Intermediarios locales }\end{array}$ & $\begin{array}{l}\text { Cuando ambos compiten por la obtención } \\
\text { del recurso forestal. }\end{array}$ & Socio-económico \\
\hline & $\begin{array}{l}\text { INAFOR-Dueños de } \\
\text { bosque }\end{array}$ & $\begin{array}{l}\text { Cuando INAFOR no les permite cortar sin } \\
\text { permiso. }\end{array}$ & $\begin{array}{l}\text { Político, social y } \\
\text { económico. }\end{array}$ \\
\hline & $\begin{array}{l}\text { Alcaldía-Dueños de } \\
\text { bosque }\end{array}$ & $\begin{array}{l}\text { Por el cobro de impuestos por parte de la } \\
\text { Alcaldía al recurso forestal. }\end{array}$ & Económico \\
\hline & Alcaldía-INAFOR & Por la apropiación del impuesto forestal. & Político-económico \\
\hline
\end{tabular}

Fuente: Elaboración propia con datos recopilados en entrevistas, 2002.

\section{El proceso de institucionalización}

Se denomina institucionalidad a las reglas del juego que gobiernan las interacciones sociales; a la dimensión organizativa de cada sociedad; al grado de facilidad con que los miembros de las sociedades logran relacionarse para cooperar de manera mutuamente beneficiosa, y 
para resolver sus diferencias de intereses, sin llegar a conflictos y enfrentamientos (Bastiaensen, 2002:11).

La institucionalización de prácticas en el comercio de la madera ocurre cuando esta actividad, que al principio es aislada o poco usual, se repite con frecuencia creciente entre los diferentes actores sociales, porque genera resultados positivos. La mayoría de estas prácticas surgen como consecuencia de diferentes situaciones, momentos e intereses de quienes participan en el proceso de comercialización, en un contexto particular. ¿Por qué se configura este proceso de institucionalización? Veamos la siguiente ilustración.

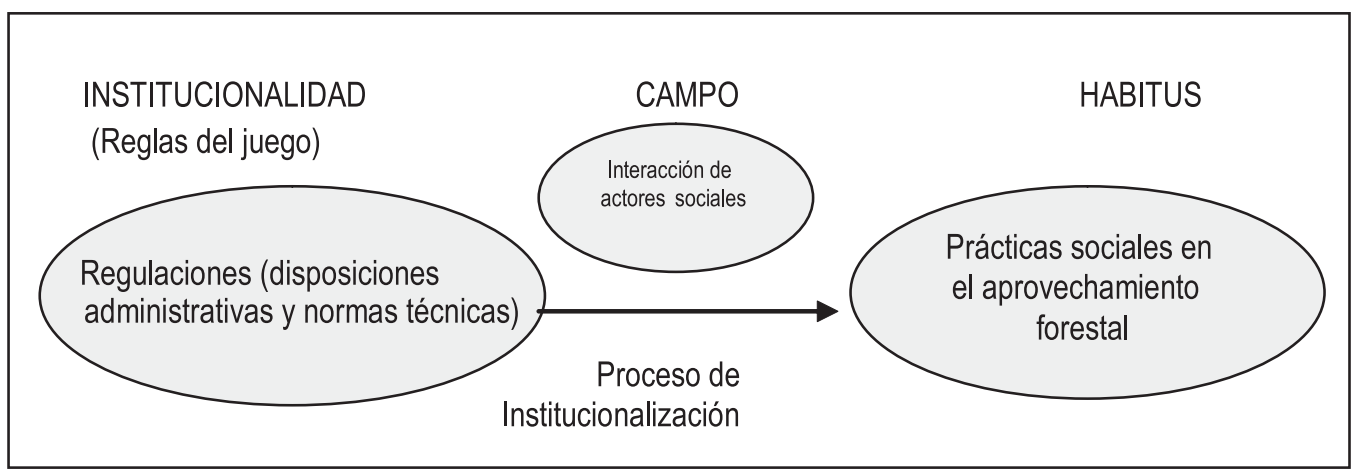

Fuente: Elaboración propia, sobre la base de experiencia investigativa.

Ilustración 4. Proceso de institucionalización de prácticas sociales

Habitus y Campo son conceptos de la sociología desarrollados por Pierre Bordieu. Se refieren a las estructuras sociales de nuestras subjetividades. Inicialmente, se constituyen en virtud de nuestras primeras experiencias (Habitus-Primario) y, más tarde, de nuestra vida adulta (Habitus-Secundario). Se refiere a la forma en que las estructuras sociales se graban en nuestra mente y en nuestro cuerpo. El Habitus incluye las estructuras mentales o cognitivas, mediante las cuales las personas manejan el mundo social. Las personas están dotadas de diferentes esquemas internalizados, por medio de los cuales perciben, comprenden, aprecian y evalúan el mundo social. Mediante estos esquemas, las personas producen sus prácticas, las perciben y las evalúan. De esta forma dialéctica, el Habitus es "el producto de la internalización de las estructuras del mundo social”. De hecho, se puede percibir el Habitus como "estructuras sociales internalizadas y encarnadas" (Bourdieu, citado por Corcuff, 1998:32).

Por su parte, el Campo es concebido por Bourdieu en términos relacionales más que estructurales. El campo es la red de relaciones entre las posiciones objetivas que hay en él. Estas relaciones existen separadas de la conciencia y la voluntad colectiva. Los ocupantes de las posiciones pueden ser agentes u organizaciones, y están contenidos por la estructura del campo. En el mundo social, se pueden identificar varios campos, cada uno con su lógica específica, generando entre los actores una creencia sobre las cosas que son importantes en el campo. El campo es un tipo de mercado competitivo en el que se emplean y desplazan varios tipos de capitales (económico, cultural, social, simbólico). 
Las posiciones de los diferentes agentes dentro del campo dependen de la cantidad y peso resultado del Capital que poseen. Cada campo esta caracterizado por una distribución desigual de los recursos y, por lo tanto, por una correlación de fuerzas entre dominantes y dominados y un campo de luchas en el que los agentes sociales se enfrentan para conservar o transformar esta correlación de fuerzas. Cada campo se caracteriza por relaciones de competencia entre sus agentes, aunque la participación en el juego implica un mínimo de acuerdo sobre la existencia del campo.

Los actores realizan su juego dentro del Campo, teniendo presente que están jugando bajo reglas que no los determinan definitivamente, ni determinan el juego. Las reglas plantean límites, pero esto no significa que no se puedan transgredir, pues también hay vacíos que pueden convertirse en oportunidades que los actores aprovecharán en función de sus intereses.

Tanto madereros como dueños de bosques y funcionarios del Estado están dotados de una serie de esquemas mediante los cuales producen sus prácticas, las perciben y evalúan y, al utilizarlas en un campo específico, las reproducen o transforman, dependiendo de sus intereses. De esta manera, diferentes razones han llevado a los actores sociales que interactúan en el campo del comercio de la madera a crear su propio habitus, que se genera por ciertas condiciones a través de reglas interiorizadas (formales o informales) que condicionan sus acciones en el aprovechamiento del recurso forestal, dentro o fuera del marco legal.

La primera noción interiorizada es que el recurso forestal existe para ser aprovechado; la segunda, que es función de la Naturaleza asegurar su reproducción (dueños de bosque y madereros); y la tercera, más propia de funcionarios del Estado, se refiere a que es obligación preservar el recurso, pues es un bien que se agota y de ahí se derivan todas las regulaciones establecidas. El habitus, en tanto estructura internalizada, revela un conflicto entre los actores, derivado de la posición que cada uno asume en torno al recurso y frente a la posición de los otros.

Aunque las reglas del juego (institucionalidad) imponen limites, son límites que pueden ser transgredidos, lo que ocurre cuando alguien encuentra vacíos y/u oportunidades para aprovechar el recurso madera bajo otras circunstancias. "A través del tiempo, cuanto más rígidas son las disposiciones, todo mundo busca como obviarlas" (Gaitán, Maderero, Rosita, 2002), porque nadie quiere quedar excluido de las ganancias que el bosque puede generar.

Veamos ahora cuáles son las prácticas más comunes que se institucionalizan, a partir de las reglas del juego establecidas en la regulación forestal.

Permisos para la extracción: esta etapa afecta a la realización de Planes de Manejo y pago de impuestos a las diferentes organizaciones del estado por actividades relacionadas con el aprovechamiento forestal. 
Cuadro 2. Tasa de aprovechamiento a especies según categorías

\begin{tabular}{|c|c|c|c|c|c|}
\hline $\begin{array}{c}\text { Categoría } \\
\text { especies de } \\
\text { madera }\end{array}$ & $\begin{array}{c}\text { Metro } \\
\text { cúbico }(\$)\end{array}$ & $\begin{array}{c}\text { Impuesto de } \\
\text { aprovecha } \\
\text { miento }(\$)\end{array}$ & $\begin{array}{c}\text { Impuesto por } \\
\text { marqueo }(\$)\end{array}$ & $\begin{array}{c}\text { INAFOR } \\
(75 \%)^{*}\end{array}$ & Alcaldía (25 \%) \\
\hline A & 19.37 & 18.27 & 1.10 & 13.70 & 4.57 \\
\hline B & 10.6 & 9.50 & 1.10 & 7.12 & 2.38 \\
\hline C & 4.02 & 2.92 & 1.10 & 2.19 & 0.73 \\
\hline D & 3.07 & 1.97 & 1.10 & 1.48 & 0.49 \\
\hline E & 2.56 & 1.46 & 1.10 & 1.095 & 0.365 \\
\hline
\end{tabular}

Fuente: elaboración en base a datos de La Gaceta del 19 de Octubre del 2001.

*La distribución de este porcentaje sólo es sobre el impuesto de aprovechamiento, ya que el marqueo queda íntegro a INAFOR.

Algunas personas obvian esta regla argumentando falta de recursos para cumplir con los trámites requeridos o, simplemente, muestran poco interés en cumplir con los trámites de INAFOR.

Normalmente, el maderero debe contratar los servicios de un técnico forestal para que le elabore el Plan de Manejo, asumiendo todos los gastos que implica su elaboración. Un permiso para extracción de madera no puede ser autorizado, mientras no se presente el correspondiente Plan de Manejo del área de donde se extraerá madera.

El INAFOR debe realizar control y/o supervisón en tres etapas: antes, durante y después del aprovechamiento, aunque este trabajo se dificulta porque la institución no cuenta con el personal y los recursos necesarios para movilizarse de una zona a otra. Las dificultades aumentan en la etapa de post-aprovechamiento, ya que invierten más tiempo y recursos que en la primera etapa.

\section{Guías}

Cuando se aprueba el permiso de extracción, los usuarios solicitan las guías a INAFOR, quien llena los datos correspondientes (nombre del usuario, origen y destino de la madera, nombre del chofer, etc.), para garantizar el uso adecuado de la guía forestal. La guía forestal se hace con cuatro copias: original, de color blanco para transporte; rosada, para el aserrío; celeste, que le queda al beneficiario; y amarilla, para el expediente de INAFOR. Su tiempo de vencimiento es de tres días (72 horas). Si no se utilizan, regresan a INAFOR sin ningún costo para nadie.

La madera debe corresponderse con el lugar de extracción indicado en la guía; sin embargo, a veces se extrae madera de zonas distintas a la especificada, por razones económicas, 0 porque el clima no permite extraer madera de ese lugar.

El espacio que se encuentra para institucionalizar esta práctica, es la falta de controles por parte de INAFOR, durante y/o después del aprovechamiento.

También se da el préstamo de guías por determinado tiempo entre algunos actores. Esto 
sucede cuando un maderero no tiene dinero suficiente para sacar su propia guía, o no tiene tiempo para esperar a que se la entreguen

Por otro lado, también se falsifican las guías: se cambian los datos para sacar la madera hacia el lugar más conveniente al maderero; o se utiliza la guía más de una vez, informando a INFOR sólo de una utilización.

Aunque el mal uso de las guías forestales está sancionado, en la práctica no se aplican las sanciones, porque INAFOR, no tiene la capacidad humana ni económica para dar seguimiento y control a estas situaciones.

\section{Subasta:}

La Subasta es una medida, mecanismo o procedimiento para disminuir las transacciones ilegales, bajo el supuesto que se castiga al maderero ilegal con una alta tasa impositiva ${ }^{9}$ (ver cuadro 3). De esa manera, se le sanciona y se le hace responsable por sus malas acciones, ya que antes de llega a la Subasta el maderero ha incurrido en gastos. También se busca presionar para que el maderero trabaje conforme las reglas establecidas. Sin embargo, en la práctica la Subasta es visualizada por muchos como un proceso de legalización de lo ilegal que, aunque conlleva altos costos, representa una opción para no quedarse fuera del negocio.

Cuadro 3. Impuesto forestal en subasta por metro cúbico (agosto-noviembre, 2002)

\begin{tabular}{|c|c|c|c|c|c|}
\hline Tipo de madera & $\begin{array}{c}\text { Estado de la } \\
\text { madera }\end{array}$ & \multirow{2}{*}{ Impuesto \$ } & \multicolumn{3}{|c|}{ Distribución del impuesto } \\
\cline { 3 - 6 } & & & $\begin{array}{c}\text { INAFOR } \\
(50 \%-75 \%)^{*}\end{array}$ & $\begin{array}{c}\text { Alcaldía } \\
(25 \%)\end{array}$ & $\begin{array}{c}\text { Policía } \\
(25 \%)\end{array}$ \\
\hline \multirow{2}{*}{ Madera Roja } & Motoaserrada & 175.4 & $87.7-131.55$ & 43.85 & 43.85 \\
\cline { 2 - 6 } & Rollo & 94.0 & $47-70.5$ & 23.5 & 23.5 \\
\hline \multirow{2}{*}{ Madera Blanca } & Motoaserrada & 87.7 & $43.9-65.8$ & 21.9 & 21.9 \\
\cline { 2 - 6 } & Rollo & 60.0 & $30-45$ & 15.0 & 15.0 \\
\hline
\end{tabular}

Fuente: datos proporcionados por Ariel Chavarría, Delegado municipal INAFOR, Rosita, 2,002.

*Cuando la Policía participa en el decomiso, se le otorga el 25\% del valor, quedándole a INAFOR el 50\% y a la Alcaldía, el 25\%; si la Policía no participa, a INAFOR le corresponde el 75\%.

Esta práctica de subastar la madera se institucionaliza cada vez más, mediante mecanismos legales implementados por el Estado, pues constituye otra forma de percibir impuestos por la actividad forestal. Lo que parecía al inicio una medida de control y sanción, se vuelve, simplemente, otro mecanismo para continuar en el negocio.

Paralelamente, se tejen otras prácticas alrededor de la Subasta, que también terminan siendo institucionalizadas. Una de ellas es el mecanismo por medio del cual, el dueño de la madera decomisada gana la Subasta como consecuencia de la organización informal de los madereros, quienes aplican normas de comportamiento de lealtad y solidaridad entre ellos. Hay una regla implícita: "hoy por ti mañana por mí", que reconoce que todos están expuestos a pasar por malas situacionea y necesitan apoyarse. De este modo, cuando alguien ya invirtió en un recurso y se enfrenta a una segura pérdida por la Subasta, la pérdida se convierte en ganancia, porque antes de la hora de ofertar la madera, los madereros se han 
aliado entre sí proponiendo precios que no alteren demasiado sus márgenes de ganancia, pero asegurando que la madera quede en manos del decomisado.

Otra forma de institucionalizar una práctica se da cuando el dueño del bosque tumba madera ilegalmente, y busca a un maderero con capacidad para pagar por esa madera en la Subasta, para llegar a un acuerdo. El maderero sabe que yendo a INAFOR y "denunciando" que hay madera tumbada ilegalmente, puede acceder legalmente a ella. Los actores ven en esta práctica un mecanismo para legalizar lo ilegal y, aunque eleve sus costos, seguirán teniendo buenos resultados. Lo hacen porque es una forma de obtener ganancias de manera legal de una actividad que, en principio, se da ilegalmente.

\section{Tranques o puestos de control:}

Para controlar el tráfico de madera, a lo largo de la ruta de comercialización hay puestos de control o tranques en los que están, o deberían estar, un funcionario de INAFOR, uno de la Policía y uno de la Alcaldía, para verificar que la madera es transportada con su documentación legal en orden.

Los madereros se sienten agredidos en los tranques pues, aunque cuentan con la autorización del INAFOR, "en el camino los miran como traficantes"10, enemigos, y a pesar de que, supuestamente $^{11}$, llevan sus papeles en orden, siempre tienen que recurrir al soborno. Por ello, muchos optan por obviar los trámites, ya que pierden tiempo y dinero; esta práctica de transportar la madera ilegal tiene que ver con la visión de recuperar la inversión en corto tiempo y sin tener que incurrir en mayores costos; por ejemplo, la realización de Planes de Manejo.

\section{Sobornos:}

Tipo 1: "soborno espontáneo"

La primera regla para que ocurra el soborno en algunos puestos de control, - de hecho, son los lugares donde se da la mayoría de la veces-, es que quien pasa con madera de forma ilegal (con documentos falsos, sin documentos, o con más metraje del indicado en las guías) busca una solución a su problema en ese momento, jugándoselas todas. Cuando se ha estudiado la manera de obviar las reglas del juego, se hacen propuestas de beneficio personal (dinero en efectivo) a los funcionarios "representantes de los intereses del Estado", contando con los bajos salarios y las malas condiciones laborales que les proporciona el Estado para que se mantengan en su puesto.

Se seduce al funcionario para que anteponga el beneficio personal al del Estado, utilizando los problemas económicos de los asalariados, y su visión cortoplacista originada en la inseguridad laboral de los funcionarios del Estado que, aun conscientes de la deforestación del bosque, terminan prefiriendo satisfacer sus necesidades económicas incrementando sus ingresos por la vía del soborno, y no por la del incremento salarial. 


\section{Tipo 2: "Soborno planificado"}

Este tipo de soborno se manifiesta cuando los funcionarios del Estado (sea del INAFOR, Alcaldía o Policía) han establecido arreglos o alianzas para transportar la madera ilegalmente. Es decir, cuando no es la primera vez que lo hacen y los madereros o transportistas conocen hasta el monto para dejar "contento(s)" a quien(es) está(n), supuestamente, controlando el correcto transporte del recurso forestal.

La existencia de los dos tipos de soborno está favorecida por ciertas condiciones: el Estado confía en sus funcionarios, pero éstos están descontentos con su salario; el comerciante sabe del descontento de los funcionarios y, por ello, les ofrece dinero para agilizar su viaje; los funcionarios están solos, nadie los ve ni los controla: es decir están en las condiciones perfectas para ser sobornados.

\section{El Peaje:}

El incremento en la actividad maderera, el constante deterioro de la carretera y los altos márgenes de ganancia que obtienen los madereros fue razón suficiente para que las Alcaldías Municipales establecieran el peaje, es decir, un pago por circular con madera por el territorio municipal. El peaje está respaldado por las normas que el Estado concede a las Alcaldías, y se vuelve un mecanismo de las Municipalidades para aumentar su participación en la apropiación de la riqueza generada por el bosque.

Actualmente, todas las municipalidades en la ruta de comercialización de la madera (Rosita, Siuna, Mulukukú, Muy Muy, Boaco, Tipitapa y Managua), han establecido esta practica común o regla que establece que cada camión que circula transportando madera, debe pagar un peaje para que continuar su ruta. De lo contrario, no se les permite cruzar por sus territorios.

¿Por qué se institucionalizan estas prácticas? La respuesta a esta pregunta puede encontrarse en diferentes factores:

- El contenido de la Ley forestal y la flexibilidad en su aplicación. Por un lado, al ser formulada desde el nivel central, la ley no toma en cuenta las particularidades de cada región o lugar donde se da la actividad forestal, para que sus habitantes tengan acceso al recurso de una manera equitativa y racional. Del otro lado, se plantea la elaboración de Planes de Manejo y pago de impuestos pre-aprovechamiento por la actividad forestal; sin embargo, las comunidades indígenas, que poseen la mayoría de áreas boscosas (Ej. comunidad de Wasakín con 36,000 hectáreas), no tienen recursos económicos para pagar dichos planes e impuestos, y recurren a madereros que sí pueden pagarlos, quedándoles una mínima parte del valor agregado del bosque (1.89\% para la madera roja y $2.68 \%$ para la madera blanca, aproximadamente). Adicionalmente, les queda un sinsabor porque el Estado les cobra por algo que consideran suyo y, cuando no consiguen financiamiento, tumban sin autorización del Estado porque, según sus palabras, "nosotros no comemos bosque, sino lo que éste nos da”. 
En este caso, el vacío está en que la Ley no contempla incentivos para que los dueños de bosque (comunales o privados) vean en él una inversión a largo plazo. “¿Para qué cuidar algo que el Estado dice que le pertenece y que, además, ni me paga por hacerlo? Mejor tumbar, vender y satisfacer temporalmente las necesidades básicas" (opinión de un comunitario).

Por otra parte, existe un incumplimiento total al Artículo 15, capítulo III de las disposiciones, referido al control de los recursos forestales, sobre la reposición de cada árbol cortado con la siembra de 20 plantas de la misma especie o superiores, en el área afectada. Las plantas deberían obtenerse simultáneamente con el aval Municipal, lo que no sucede por diferentes razones: la municipalidad no dispone de presupuesto para mantener un inventario de plantas y, en su defecto, deja el trabajo a la regeneración natural.

Hay estipulada una multa de 1,000 ó 5,000 córdobas para quienes tumban árboles no autorizados; sin embargo los campesinos cortan a tala rasa, queman los bosques para cultivos y/o potreros y no hay medidas para evitarlo. Estos hechos dejan como mensaje que nadie se preocupa por la reposición del recurso.

- Lejanía de mercados e inseguridad en el traslado: las grandes distancias a los diferentes mercados, nacionales o internacionales y las pésimas condiciones de los caminos no posibilitan la efectividad de los puestos de control, ya que los funcionarios de las organizaciones (INAFOR, Alcaldía, Policía) explican que, con frecuencia, son amenazados con armas por quienes transportan madera ilegalmente para que los dejen pasar; si se resisten, corren el riesgo de que les disparen y, como no tienen apoyo armado cerca, no pueden hacer nada.

A ello se agrega que, en algunos puestos, hay funcionarios que son blanco fácil de soborno, porque no hay personal encargado únicamente de supervisar la correcta actuación de funcionarios y madereros.

- $\quad$ Poca incidencia de Gremios, ONGs y agencias de cooperación en el negocio de la madera: Las únicas organizaciones con presencia en la zona de Rosita, en el negocio de la madera, son: REPROMAB, CATIE y AFONIC y ninguna tiene incidencia en la actividad comercial de la madera. El apoyo que canalizan a los grupos comunitarios se concentra en la fase productiva (manejo de plantaciones) o en a actividades para la conservación de los recursos.

Finalmente, si se revisa la forma en que se distribuyen los ingresos en el proceso de la extracción y comercialización interna de la madera, resulta que el valor del metro cúbico de madera va variando de manera sustantiva dependiendo de los procedimientos por los que circula, como se resume en la sección siguiente. 


\section{6. ¿Cómo se distribuyen los ingresos en el mercado de la madera?}

Los cuadros 4 y 5 , ponen de manifiesto que a través de la interacción de los diferentes actores sociales se va estableciendo el precio, mediante negociaciones que resultan más beneficiosas para unos que para otros.

Cuadro 4. Formación del precio de madera blanca (triángulo minero-fuera del país) metro cúbico. Categoría B (agostonoviembre, 2002)

\begin{tabular}{|c|c|c|c|c|c|c|c|c|c|c|c|c|c|c|}
\hline \multirow{3}{*}{ Indicador } & \multirow{3}{*}{ 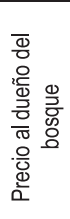 } & \multirow[b]{3}{*}{ 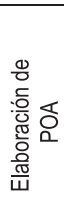 } & \multicolumn{6}{|c|}{ Equipo de extracción } & \multirow[t]{3}{*}{ Aserrado } & \multicolumn{3}{|c|}{ Impuestos } & \multirow{3}{*}{\begin{tabular}{|l|} 
Otros \\
costos y \\
margenes \\
de \\
interme \\
diación \\
\end{tabular}} & \multirow{3}{*}{\begin{tabular}{|l} 
Valor \\
exporta \\
do o \\
precio \\
FOB
\end{tabular}} \\
\hline & & & \multirow[t]{2}{*}{ Tumba } & \multirow[b]{2}{*}{ 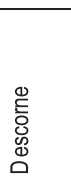 } & \multirow[b]{2}{*}{ 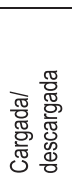 } & \multicolumn{3}{|c|}{ Transporte } & & & & & & \\
\hline & & & & & & $\begin{array}{l}\text { Patio de } \\
\text { montaña }\end{array}$ & \begin{tabular}{|l|} 
Patio de \\
todo \\
tiempo
\end{tabular} & $\begin{array}{l}\text { 은 } \\
\text { 离 } \\
\text { 足 }\end{array}$ & & $\begin{array}{l}\text { 号 } \\
\text { 殅 } \\
\underline{\Sigma}\end{array}$ & $\frac{\frac{\pi}{0}}{\frac{0}{0}}$ & 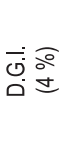 & & \\
\hline US \$ & 9.8 & 1 & 0.59 & 0.78 & $\begin{array}{r}7+7 \\
=14^{*}\end{array}$ & 10 & 14 & 12 & 43.8 & $\underset{*}{8.225^{*}}$ & 5.21 & 14.61 & 231.4 & 365.38 \\
\hline$\%$ & 2.7 & 03 & 0.2 & 0.2 & 3.8 & 2.7 & 3.8 & 3.3 & 12 & 2.2 & 1.4 & 4 & 63.3 & 100 \\
\hline
\end{tabular}

Fuente: Elaboración propia en base a entrevistas semi- estructuradas y análisis de archivos (la Gaceta, 19 de octubre del 2001).

+ Al no encontrar ningún archivo con el precio FOB, se estimó su valor en base a estadísticas del Centro de Trámites de las exportaciones (CETREX, 2002), sobre exportaciones de madera aserrada.

*El primer monto corresponde al paso del lugar de extracción al patio de montaña y el segundo, al aserrío.

** Impuesto de aprovechamiento por categoría, más impuesto de marqueo (este último de 1.10 para todas las especies).

Cuadro 5. Formación del precio de madera roja (triángulo minero- fuera del país) metro cúbico. Caoba (agostonoviembre, 2002)

\begin{tabular}{|c|c|c|c|c|c|c|c|c|c|c|c|c|c|c|}
\hline \multirow{3}{*}{ Indicador } & \multirow[b]{3}{*}{ 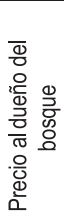 } & \multirow[b]{3}{*}{ 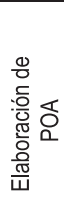 } & \multicolumn{6}{|c|}{ Equipo de extracción } & \multirow[b]{3}{*}{ 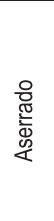 } & \multicolumn{3}{|c|}{ Impuestos } & \multirow{3}{*}{\begin{tabular}{|l} 
Otros \\
costos \\
y \\
márgenes \\
de \\
interme \\
diación
\end{tabular}} & \multirow{3}{*}{\begin{tabular}{|l|} 
Valor \\
exportado \\
0 \\
precio \\
FOB
\end{tabular}} \\
\hline & & & \multirow[t]{2}{*}{ Tumba } & \multirow[b]{2}{*}{$\begin{array}{l}* 0 \\
\stackrel{\otimes}{0} \\
0 \\
0 \\
0\end{array}$} & \multirow[b]{2}{*}{ 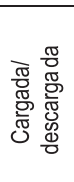 } & \multicolumn{3}{|c|}{ Transporte } & & & & & & \\
\hline & & & & & & $\begin{array}{l}\text { Patio de } \\
\text { montaña }\end{array}$ & $\begin{array}{l}\text { Patio } \\
\text { de todo } \\
\text { tiempo }\end{array}$ & $\begin{array}{l}\text { 은 } \\
\text { D. } \\
\text { 足 }\end{array}$ & & $\begin{array}{l}\text { 号 } \\
\text { 崖 } \\
\underline{\underline{z}}\end{array}$ & $\frac{\frac{\pi}{0}}{\frac{0}{\mathbb{N}}}$ & 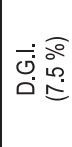 & & \\
\hline US \$ & 11.4 & 1 & 0.59 & 29.2 & 14 & 29.2 & 14 & 12 & 43.8 & 14.8 & 13.05 & 45.16 & 373 & 602.13 \\
\hline$\%$ & 1.89 & 0.2 & 0.098 & 4.85 & 2.32 & 4.85 & 2.32 & 1.99 & 7.27 & 2.46 & 2.17 & 7.5 & 62.1 & 100 \\
\hline
\end{tabular}

Fuente: Elaboración propia en base a entrevistas semi- estructuradas y análisis de archivos (la Gaceta, 19 de octubre del 2001).

*Boncheo: extraer el árbol hasta donde pueda ser cargado en el camión.

A todos los interesados en el comercio de la madera, se le presentan, en determinado momento, elementos que dificultan o disminuyen la captación de ingresos en la actividad forestal; entre estos elementos podemos identificar: obstáculos y trampas.

En el ámbito institucional, los obstáculos son:

- Existe demasiada burocracia en lo referido a la aprobación de permiso.

- La elaboración de Planes de Manejo es costosa ${ }^{12}$ (a un dólar por metro cúbico) y no todos tienen acceso al capital financiero para pagarlo. 
- El INAFOR es inflexible en el pago de los impuestos, aunque sean sobre preaprovechamiento. Se establecen de esta manera para evitar engaños por parte de los madereros. En las delegaciones de INAFOR ocurre una descentralización de funciones, no de ingresos, lo que limita el nivel de operaciones.

En el ámbito local se enfrenta como adversidades:

- Factor climático: se tienen 10 meses de invierno y solamente dos de verano.

- El mismo Municipio no presta las condiciones de infraestructura, puesto que ni calles pavimentadas tiene y los caminos, que son las principales vías de acceso, están totalmente desbaratados" (Stamp, Inspector INAFOR, Rosita).

Respecto a las prácticas:

- Tumbar madera, obviando procedimientos legales.

- Competencia desleal en el mercado por parte de ilegales.

- $\quad$ Avance de la frontera agrícola.

- Mala fe de usuarios que engañan a la gente, diciendo tener permisos de Managua y es falso" (Sánchez, Director Territorial, INAFOR Central).

Por otra parte, "en este negocio, el que menos corre alcanza un venado" (Dianer, Delegado Distrital, Rosita). Esta expresión pone de manifiesto el nivel de desconfianza que hay en las transacciones comerciales de la actividad maderera; se corren muchos riesgos y en la medida en que se van insertando en el negocio, los madereros van conociendo los mecanismos para engañar y/o evitar ser engañados. Sin embargo, no todos logran aprender la lección exitosamente, puesto que su capital económico no es lo suficientemente fuerte para soportar las pérdidas monetarias que implica el ser engañado y, como consecuencia, quiebran financieramente (en el caso de los inversionistas es el fracaso y, por parte de los dueños de bosque, significa el agotamiento de sus áreas boscosas).

\section{Conclusiones}

1. A estas prácticas generalizadas, antecede un proceso de institucionalización (proceso mediante el que los diferentes actores van aceptando las reglas del juego y las van modificando de acuerdo a su interés). Una práctica que. en principio, surge aisladamente pero tiene un resultado positivo para quien la lleva a cabo, se convierte en una práctica de uso cotidiano que luego se asume algo como normal, legitimándose. De esa forma, su resultado es reconocido como algo natural, en el sentido de que no se cuestiona su origen porque ya está institucionalizado, aunque también puede ser modificada.

2. La mayoría de estas prácticas surgen como consecuencia de diferentes situaciones, momentos e intereses que contempla cada uno de los que participan en las negociaciones en el campo de la comercialización, además de los factores que permiten su realización, como son:

- Contenido de la Ley forestal y flexibilidad en su aplicación: hay descontento por la forma en que participa el Estado en el aprovechamiento forestal (sólo castiga en términos de impuestos, pero no incentiva a los otros actores para que vean en el 
bosque una inversión a largo plazo). Por otra parte, hay flexibilidad en la aplicación de las regulaciones por parte del INAFOR, por las condiciones socio-económicas de la zona (desempleo, precaria infraestructura vial, pobreza, etc.) y del INAFOR, que depende de la actividad de los ingresos de la actividad forestal para mantener operaciones.

- Lejanía de mercado: las largas distancias entre uno y otro mercado, aunado a la falta de condiciones para hacer efectivos los controles, prestan las condiciones para que se den alianzas "ilícitas" (corrupción) entre madereros y funcionarios estatales.

- Poca incidencia de gremios, ONGs y agencias de cooperación en el negocio de la madera: la presencia de las ONGs en el municipio de Rosita, ligada al comercio de la madera, se limita a tres: Red de Protección y Manejo de Bosques del Triángulo Minero y Prinzapolka (REPROMAB), Centro Agronómico Tropical de Investigación y Enseñanza (CATIE) y la Asociación de Forestales de Nicaragua (AFONIC); cuya participación es igualmente limitada, porque no han logrado adquirir legitimidad a nivel local, porque la población local no siente que contribuyan a mejorar sus condiciones de vida.

- Multiplicidad de intereses: por la heterogeneidad de los actores involucrados en el recurso forestal, se da una multiplicidad de intereses cuando interactúan, buscando cómo no ser excluidos de los beneficios de la comercialización de los árboles, permitiendo de esta forma la aceptación y repetición de prácticas cuyos resultados sean positivos a sus intereses.

3. Los actores están dotados de una serie de esquemas (Habitus), mediante los cuales producen sus prácticas, las perciben y, al utilizarlas en un ámbito específico, las reproducen 0 transforman de acuerdo a sus intereses.

\section{Recomendaciones}

1. Es necesario reformar el Reglamento Forestal porque no contempla a los que tienen menos recursos económicos. Se requiere una Ley de incentivos para que la población local tenga interés en cuidar el recurso forestal, porque van a considerar que es algo que les pertenece y con ello pueden mejorar su vida.

2. La cooperación internacional y el Estado deben dirigir esfuerzos para entender la lógica que se teje en torno al comercio de la madera, principalmente los actores que cuentan con mayor capital y ejercen el control sobre las reglas del juego.

3. Las universidades e institutos de investigación deben promover estudios sobre las barreras de entrada en la comercialización de la madera y, de esta forma, incidir en una mejor participación en los primeros eslabones de la cadena.

Estas recomendaciones serían efectivas, siempre y cuando hubiera voluntad política por parte de los diferentes actores sociales involucrados en el proceso de comercialización de la madera para llevarlas a cabo. 


\section{Notas}

3 Este técnico es independiente del INAFOR.

4 Este es el caso de Extracfor S. A., que es una empresa que presta servicios de alquiler de equipos de extracción.

5 Caso de PRADA S.A., empresa procesadora de plywood, ubicada en el municipio de Rosita.

6 REPROMAB está laborando en las instalaciones de INAFOR, ya que no tienen presupuesto para tener oficinas propias, aunque están gestionándolo.

7 Ambos tipos de proveedores, según entrevista con Lesbia Cruz, representante legal de PRADA S.A., les proveen entre 18 y 20,000 metros cúbicos de madera, anualmente.

8 Ejemplo de ello es el Plan de Manejo de 4,950 hectáreas que PRADA tiene en la comunidad de Layasiksa; previo a la realización de este plan, la empresa hizo un arreglo con la comunidad, a través del cual la comunidad recibe 6 dólares por metro cúbico extraído, encargándose PRADAS. A. de todo el proceso relacionado con el aprovechamiento forestal.

9 El impuesto en Subasta para la Caoba, que está en la categoría A, es de \$94 en madera en rollo, en comparación con los \$19.37 por impuesto de aprovechamiento y marqueo, que pagaría si trabajase legalmente.

10 Expresión de transportista.

11 Decimos "supuestamente" porque, en la mayoría de los casos, llevan más madera que la estipulada en la guía para poder, según ellos, aguantar las altas tasas impositivas.

12 Costoso, en tanto que su pago es pre-aprovechamiento y los dueños de bosque no tienen capital económico para pagarlo; sin embargo si se compara con otros costos, es relativamente barato.

\section{Referencias bibliográficas}

-BASTIAENSEN, J. et al.(2002). Crédito para el desarrollo rural en Nicaragua. Un enfoque institucional sobre la experiencia del Fondo de Desarrollo. Managua, Nitlapán UCA. $1^{\text {a }}$ edición.

-CENTRO DE TRÁMITES DE LAS EXPORTACIONES-CETREX (2002). Exportaciones autorizadas de madera aserrada. Período Enero-Agosto de 2002

-CRUZ, L. (2002). Entrevista al representante legal de PRADA, Rosita, Nicaragua, 25 de Octubre

-CHAVARRÍA, A. (2002). Entrevista al delegado municipal del INAFOR, Rosita, Nicaragua, 24 de Octubre

-CRCUFF, P (1998). Las nuevas sociologías: el constructivismo estructuralista de Pierre Bourdieu. Madrid, Alianza Editorial S.A.

-GAITÁN, J. (2002). Entrevista a maderero intermediario, Rosita, Nicaragua, 24 de Octubre. -La Gaceta (2002). Diario Oficial. Managua, Nicaragua.

-LOZARES, C. (1999). Introducción a las redes sociales. Cursos de post licenciatura en Centroamérica. Managua. UCA.

-MENDOZA, R. y FLORES, S. (2001). Espacios, oportunidades y experiencias de pequeños productores para acceder al mercado. Managua, Nitlapán, UCA.

-SÁNCHEZ, D. (2002). Entrevista al delegado distrital del INAFOR, Municipio de Rosita, Nicaragua, 31 de Octubre.

-SÁNCHEZ, S. (2002). Entrevista al director de Ordenamiento Territorial del INAFOR, Managua, Nicaragua, 3 de Diciembre.

-STAMP, H. (2002). Entrevista al inspector de INAFOR Rosita, Nicaragua, 13 y 15 de Agosto; 6 de Noviembre. 